\title{
O discurso de progresso no jornal "A Voz do Povo" entre 1927 e 1937
}

\section{The discourse of progress in the newspaper "A Voz do Povo" between 1927 and 1937}

\author{
Johnny Lucas Borges Araujo ${ }^{A}$ \\ Diego Fernando Rodrigues Azorli ${ }^{\mathrm{B}}$ \\ AndRÉa Aparecida Zacharias ${ }^{C}$ \\ Fabiana Lopes da CUnHa ${ }^{\text {D }}$
}

a Professor de Educação Básica na Secretaria de Educação do Estado de São Paulo, Mestre em Geografia pela Universidade Estadual Paulista (Unesp), campus de Rio Claro.

E-mail: jborgesaraujo@gmail.com

${ }^{\text {b }}$ Professor de Educação Básica na Secretaria de Educação do Estado de São Paulo, Mestre em História pela Universidade Estadual Paulista (Unesp), campus de Assis.

E-mail: diegoazorli@yahoo.com.br

\begin{abstract}
c Professa doutora da Universidade Estadual Paulista (Unesp), campus de Ourinhos, professora do Programa de Pós-graduação em Geografia (M e D) da Universidade Estadual

Paulista (Unesp), campus de Rio Claro.

E-mail: andrea.zacharias@unesp.br

d Professora doutora da Universidade Estadual Paulista (Unesp), campus de Ourinhos, professora do Programa de Pós-graduação em História (M e D) da Universidade Estadual

Paulista (Unesp), campus de Assis.

E-mail: fabiana.cunha@unesp.br
\end{abstract}

\begin{abstract}
Neste trabalho, procuramos recompor memórias a partir de fontes impressas (exclusivamente do jornal $A$ Voz do Povo) e analisar o discurso de progresso existente em seus exemplares no período de 1927 a 1937. Por se tratar de uma memória de lugar, cumpre trabalhar com a recuperação temporal e local. Por isso, surgem questões vinculadas à memória e à nossa principal fonte documental (o jornal), a exemplo de como a imprensa retratava a cidade de Ourinhos e como esse periódico retratava a população. Embora houvesse outros jornais locais que circularam no mesmo período, não há exemplares sequenciais preservados ou que não se encontrem em péssimo estado. Portanto, vemos nossa fonte como privilegiada (por apresentar sequência) para abordarmos o tema que queremos retratar. Assim, coloca-se o discurso de progresso em perspectiva a fim de tentar compreender a sociedade ourinhense do período e auxiliar na reconstrução de parte dessa narrativa histórica.

Palavras-chave: história, jornais, memória, progresso, vida cotidiana.

Based on the printed newspaper $A$ Voz do Povo, this paper pieces together memories and analyzes the discourse of progress found in its issues from 1927 to 1937. Dealing with the memory of a place, we must focus on recovering a time and place, addressing issues related to memory and to our main documentary source (the newspaper), such as: how the press described the city of Ourinhos and its population, etc. Despite existing other local newspapers that circulated in the same period, we have no sequential copies preserved or they are in very poor condition. This makes $A$ Voz do Povo a privileged source to investigate the topic at hand. By analyzing the discourse of progress present in the newspaper, we seek to understand the society in 19th century Ourinhos and help piece together part of this historical narrative.
\end{abstract}

Keywords: history, newspaper, memory, progress, daily life. 


\section{INTRODUÇÃO}

Tanto Pollak (1992) quanto Bosi (1994) declararam que memória é trabalho, visto que há um processo de seleção e conservação das informações recebidas, de forma que as imagens armazenadas possam ser acessadas posteriormente, quando necessário. A rememoração dessas imagens passadas arquiteta a história de vida e permite nos situar no tempo e espaço. No entanto, ao trazer para reflexão a imagem dos eventos passados, não o fazemos em sua totalidade, porque, ao processarmos informações passadas, selecionamos apenas aquelas que revelaram dados importantes para a discussão proposta. Assim, um ponto importante que vale destacar é que lembrar não é reviver o passado exatamente como ocorreu, mas reconstruí-lo com base no momento atual.

A memória é fundamental para um grupo porque está ligada à construção de sua identidade. Ela é fruto de um trabalho de seleção e organização do que é vital para o sentido de pertencimento, de continuidade, de unidade e, portanto, de identidade.

Com a memória, nomeia-se o que está ausente e já aconteceu, mas que de alguma forma ainda está presente, pois atribui-se sentido às vivências de uma comunidade ou sociedade, vivências cuja continuidade na memória requer a prática. Ao longo do tempo, os atores deixam rastros de sua identidade corporificados na história e nos espaços, o que os torna também parte da memória.

Portanto, pessoas são sujeitos com identidades pessoais e coletivas; "es la autopercepción de un sujeto en relación con los otros, a lo que corresponde a su vez, el reconocimiento y la apropiación de los otros sujetos" (GIMÉNEZ, 1997, p. 4), que emerge e se declara apenas no enfrentamento de outras identidades no processo de interação social.

A identidade não é estática, mas dinâmica, viva e está sempre em construção. É um mecanismo móvel, continuamente formado e transformado em relação às formas como os atores se representam ou se designam nos sistemas culturais que os rodeiam. Há lugares de memória, lugares particularmente ligados a lembranças, que podem ser pessoais - quando, por exemplo, um indivíduo se recorda do quintal de seus avós, ou seja, baseado em algo que ele vivenciou - ou coletivas, como os lugares de comemoração ou um monumento aos mortos de determinada guerra. Tais memórias deixam uma marca nos lugares e para entendê-los, é preciso resgatá-las, conforme Poulet (1992, p. 5455), que diz que "graças à memória o tempo não está perdido, e, se não está perdido, também o espaço não está. Ao lado do tempo reencontrado, está o espaço reencontrado".

Assim, é preciso fazer um resgate dos registros produzidos e cruzá-los com outras fontes documentais para obter uma visão mais ampla das memórias. "As imagens têm potencialidades implícitas, histórias dentro de si. O espaço geográfico é a condição de realização dessas histórias e atribui a cada coisa, formas de nossas relações, um lugar" (AGUIAR, 2003, p. 142). Como pontuado por Nora (1993, p. 25), "a memória perdura em lugares, como história em acontecimentos". Assim,

[...] não há memória coletiva que não aconteça num contexto espacial. Ora, o espaço é uma realidade que dura: nossas impressões se sucedem umas às outras, nada permanece em nosso espírito e não compreenderíamos que seja possível retomar o passado se ele não estivesse conservado no ambiente material que nos circunda. É ao espaço, ao nosso espaço - o espaço que ocupamos, por onde passamos muitas vezes, a que sempre temos acesso e que, de qualquer maneira, nossa imaginação ou nosso pensamento a cada instante é capaz de reconstruir - que devemos voltar nossa atenção, é nele que nosso pensamento tem de se fixar para que essa ou aquela categoria de lembranças reapareça. (HALBWACHS, 2013, p. 170)

Por se tratar de uma memória de um lugar, tem-se que trabalhar o resgate da história do e no lugar. Na cidade de Ourinhos, área piloto de nossa proposta metodológica, temos o jornal $A$ Voz do Povo, com o qual trabalhamos a fim de decifrar uma teia que compõe as histórias dessa cidade e analisar os espaços onde elas se encontram. Esses espaços têm uma relação intrínseca com o homem, visto que são construções sociais. Assim, o trabalho com memória fortalece o sentimento de identidade e pertencimento das pessoas através do estímulo à pesquisa das história $\mathrm{e}$ memória do objeto (lugar) analisado.

Face ao exposto, este artigo tem como objetivo analisar o discurso de progresso no periódico $A$ Voz do Povo em sua primeira década, ou seja, de 1927 a 1937, e nas obras dos autores que perpetuaram a história da cidade, relacionando-os com a fase de expansão vivida na cidade de Ourinhos no período por nós analisado.

\section{Procedimentos metodológicos}

O estudo da memória a partir do resgate da história do e no lugar teve como fundamentação a proposta 
teórico-metodológica de Araújo (2021), reproduzida na figura 1, que propõe duas fases para seu entendimento:

Fase I: Análise documental. Momento em que triamos os 670 exemplares disponíveis do jornal $A$ Voz do Povo, publicados entre os anos de 1927 e 1944. Foram criadas tabelas para organizar os materiais, com ano, número e data de publicação. Foram elencadas categorias para analisar as notícias de acordo com os temas mais abordados, sendo elas divididas em dois grupos: infraestrutura (água e esgotos, eletricidade, ruas e praças, transporte) e discursos morais (alcoolismo, saúde, violência urbana, problemas sociais, religião, sexualidade, discursos sobre as mulheres). Elaboramos fichamentos de cada um dos exemplares e transcrevemos na íntegra as informações obtidas, mantendo a grafia utilizada na época da escrita do jornal. Com isso, um banco de dados foi gerado;

Fase II: Interpretação dos relatos e construção da narrativa histórica. Com base nas informações levantadas nas análises do jornal $A$ Voz do Povo, e nas entrevistas realizadas por Romero e Moraes (2004) e nas contribuições de textos de Del Rios (2015), Boscariol (2008), Silva (2009) e Dias (2014), construímos uma narrativa sobre o desenvolvimento urbano de Ourinhos entre os anos de 1918, quando foi emancipada, e 1944, evidenciando o ideário de progresso veiculado no discurso do jornal e o contrapondo à realidade material da cidade.

Figura 1. Etapas metodológicas da pesquisa.

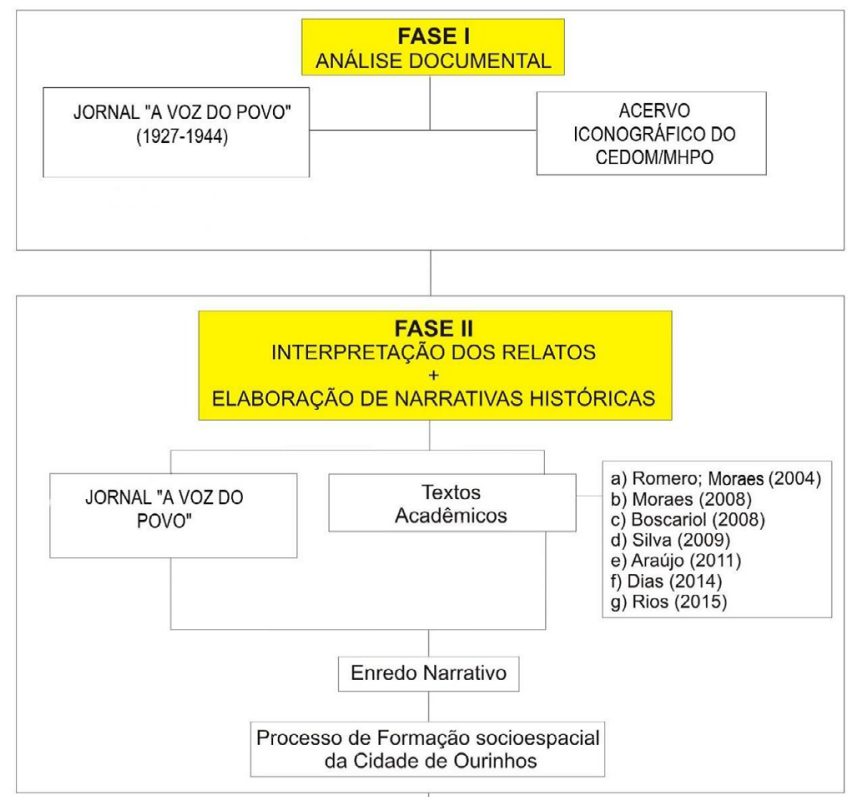

Fonte: Araújo (2021).

\section{Resultados E Discussões}

\section{Caracterização do periódico A Voz do Povo}

$A$ Voz do Povo (figura 2, imagem 1) foi um jornal local da cidade de Ourinhos que esteve em circulação entre os anos de 1927 e 1953. As cópias físicas estão preservadas no Museu Histórico e Pedagógico de Ourinhos (MHPO), onde existem apenas exemplares publicados entre 1927 e 1951 que foram parcialmente digitalizados e alocados no site Tertuliana ${ }^{1}$, onde há edições publicadas de 1927 a 1949. Além disso, o Centro de Documentação e Memória da Unesp Ourinhos (Cedom) possui cópias dos periódicos de 1927 a 1951.

Em seu primeiro decênio, houve a publicação de 320 edições, das quais analisamos os 287 números disponíveis, com base no acervo do site Tertuliana e do Gedom. Na primeira fase do periódico, nota-se que não há linearidade na estrutura, que passou por mudanças constantes nos anos de 1927 a 1930. O jornal começa a ser sequencial a partir de 1931, quando se torna semanal, havendo duas interrupções: entre 17/07/1932 e 05/07/1933 (quase um ano); e entre 30/12/1934 e 18/05/1935 (quase seis meses). A partir do primeiro quinquênio, o número de propagandas e o total de páginas se avolumam². O tamanho das páginas aumenta a partir do ano de 1934 e, após 1938, cresce novamente.

O jornal não possui colunas fixas e seus assuntos são variados. Constitui-se de artigos de diversos colaboradores, dos quais alguns são recorrentes, como Dr. M. Pimentel, Prof. Constantino A. Molina, Chereta, Beleomar e Jorá de Andy, e chegou a imprimir 600 exemplares por semana em $1937^{3}$. A direção do jornal era de Joaquim de Azevedo, que se manteve no posto até 1945, e a propriedade era de M. Gonçalves.

Nesta lógica, para a narrativa dos resultados procuramos atentar para os menores detalhes: aquilo que é objetivo (o explícito) e aquilo que se encontra nas entrelinhas (o subjetivo). A cidade de Ourinhos (figura 2, imagem 2) estava em plena expansão e as notícias versavam sobre os mais diversos temas: calçamento das ruas, iluminação, realização de núpcias, aniversários etc. Mas, se nos detivermos atenciosamente a esses textos,

1 Disponível em: http://www.tertuliana.com.br.

2 Para mais informações sobre a configuração dos primeiros anos do jornal, vide Araujo e Cunha, 2017.

3 A Voz do Povo. 16/01/1937, p. 4. 
perceberemos que alguns temas eram mais enfatizados que outros e que a tônica do discurso variava de coluna para coluna.

O anseio pelo progresso, constatado no jornal, também era marcado por contradições e ambiguidades: enquanto por um lado louvava-se a ciência e o domínio da natureza pelo homem, por outro impunha-se as ideias de ordem (que chegava aos lares na figura patriarcal do chefe de família) e do preconceito ao trabalho braçal e às manifestações populares em prol de discursos prontos de civilidade; e se enalteciam os bailes e os hábitos sociais das classes mais abastadas, bem como o embelezamento da cidade e a expulsão da pobreza (COSTA; SCHWARCZ, 2000).

Frente ao fato de que a memória coletiva ${ }^{4}$ é um objeto de poder, pontuamos que $A$ Voz do Povo acabava por organizar e sedimentar as memórias populares e orais, por ser um veículo impresso e, portanto, preferido para conferir veracidade aos fatos (embora nem sempre se baseasse em fatos, mas sim em opiniões de seus colaboradores), num período quando havia apenas o rádio nos lares brasileiros. Mais tarde, os autores, em sua grande maioria ourinhenses, que perpetuariam a memória dessa cidade em seus livros, operariam também uma construção de memórias que nem sempre correspondem, de fato, ao que ocorreu, mas são produtos de desejos e sonhos (BOSI, 1994).

4 Trabalhamos com a definição de memória coletiva de Le Goff (2003, p. 419): "Fenômeno individual e psicológico ( $c f$. soma/psiche), a memória liga-se também à vida social (cf. sociedade). Esta varia em função da presença ou da ausência de escrita ( $c$. oral/escrito), e é objeto da atenção do Estado que, para conservar os traços de qualquer acontecimento do passado (passado/presente), produz diversos tipos de documento/monumento, faz escrever a história (cf. filologia), acumular objetos (coleção/objeto). A apreensão da memória depende deste modo do ambiente social (cf.espaço social) e político (cf. política): trata-se da aquisição de regras de retórica e também da posse de imagens e textos (cf. imaginação social, imagem, texto), que falam do passado, em suma, de um certo modo de apropriação do tempo (cf. ciclo, gerações, tempo, temporalidade)" [nota de rodapé].
Figura 2. O jornal $A$ Voz do Povo e o mapa de Ourinhos.

Imagem 1: Jornal $A$ Voz do Povo; Imagem 2: Mapa de Ourinhos, década de 1930.

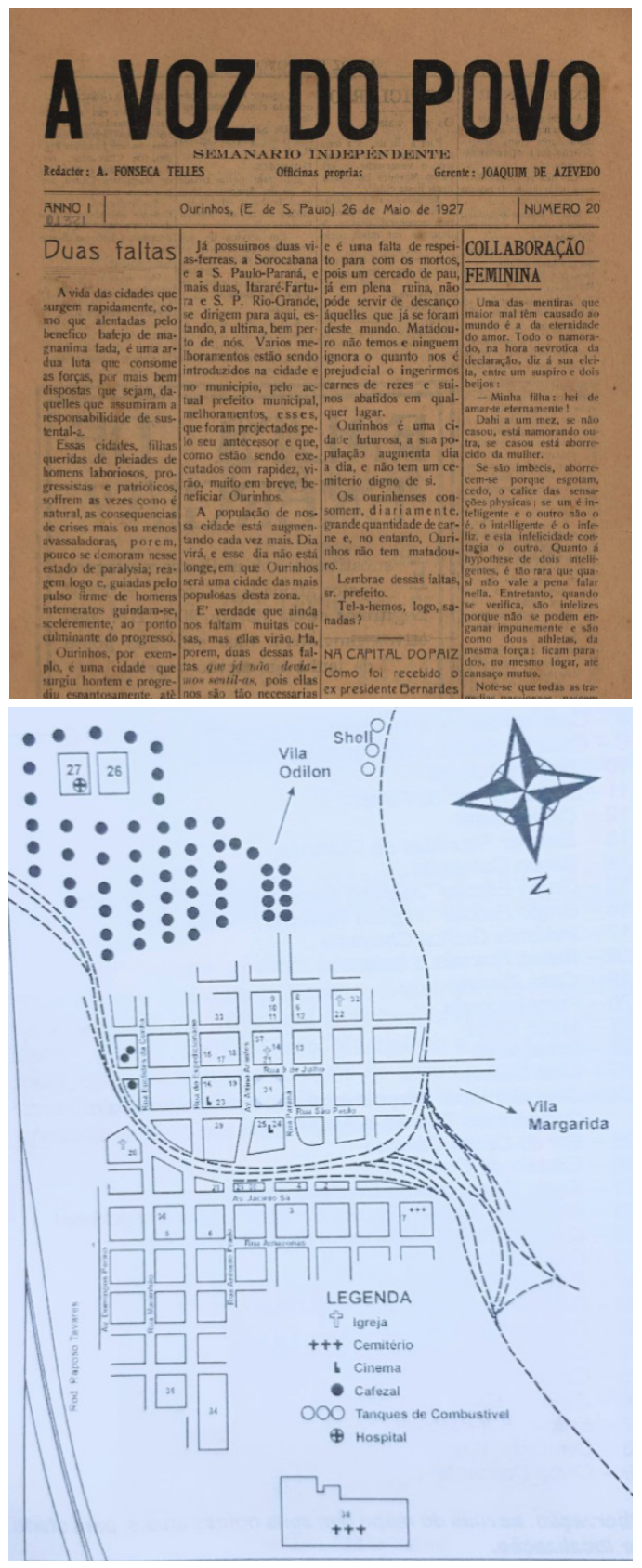

Fonte: Araújo (2021) e Moraes (2004).

\section{Cidade de Ourinhos: "Útero do progresso"}

Ourinhos nasceu em 1908, com a chegada dos trilhos da Estrada de Ferro Sorocabana, foi elevada a distrito em 1915 e a município em 1918 (DEL RIOS, 2015; ROMERO; MORAES, 2004; SILVA, 2009). Os anos subsequentes foram marcados pelo crescimento populacional, 
dada a chegada de migrantes de diversas partes do Brasil e do mundo, e pela transformação da paisagem urbana.

De 1919 a 1923, seguiram-se diversas disputas políticas de coronéis locais, envolvendo assassinatos e julgamentos que absolveram os acusados ${ }^{5}$. Em 1923, Jacintho Sá se tornou prefeito e, por meio de diversas leis e decretos, foi o responsável pela: transformação da rua Minas Gerais em uma avenida, "alargando-a para o lado de cima"; reconstrução da rua Dr. Altino Arantes e embelezamento da cidade; arborização das avenidas Jacinto Sá e Minas Gerais; e reparação da estrada da ponte do rio Pardo. Em 1926, abriu uma concorrência pública para abastecimento de água da cidade e proibiu as construções de madeira no perímetro urbano (DEL RIOS, 2015, p. 231). No mesmo período, ocorreu a construção da estação de trens da Sorocabana, que foi inaugurada no ano seguinte.

Será solenemente inaugurada, no dia 22 do corrente, a nova estação da Sorocabana, nesta cidade. Ao espírito progressista do exmo. sr. dr. Arlindo Luz, d. d. director dessa importante via férrea, é que Ourinhos deve a construcção dessa estação, uma das melhores deste ramal. (INAUGURAÇÃO da nova estação..., 1927, p. 2)

Em 1927, inaugurou-se a ponte sobre o rio Pardo, na barra do rio Turvo, e o coreto da praça Mello Peixoto, cuja autoria foi assinada pelo dr. Ernesto Rosemberger e a construção executada por Henrique Tocalino (DEL RIOS, 2015, p. 231). José Galvão, prefeito municipal em 1929, publicou um edital no mesmo ano para que os proprietários dos prédios situados à rua São Paulo, no trecho entre a avenida Altino Arantes e a rua Piauí, que possuíam meio-fio, executassem o calçamento. No mesmo edital, houve a abertura do registro de pedidos de ligação de água encanada (DEL RIOS, 2015, p. 232-233).

Paralelamente à pretensa reeducação popular que se desejava realizar, eram aventados projetos de melhoramentos básicos, imprescindíveis ao desenvolvimento, pivôs da urbanização e da passagem para a modernização tão idealizada. Teriam de ser tomadas providências rápidas, tais como a instalação de redes de esgoto e água encanada, a iluminação pública com energia elétrica, construções de pontes e pontilhões, abertura de avenidas, abertura e calçamento de ruas, ajardinamento urbano, entre outras obras. (PEREIRA, 2004, p. 27)

5 Para mais detalhes, ver capítulos 6 e 7 de Del Rios (2015).
O ideal de progresso, tido aqui como tentativa de cópia dos padrões das nações que alcançaram a modernidade, pressupunha uma ordem evolutiva das sociedades, com leis normativas, cujo avanço não poderia ser interrompido. Inclusive, o uso da palavra "moderno" gestava a síntese dos novos tempos. Nicolau Sevcenko pontua que:

[...] moderno se torna a palavra origem, o ovo absoluto, a palavra-fruto, a palavra-ação, a palavra-potência, a palavra-libertação, a palavra alumbramento, a palavrareencantamento, a palavra-epifania. Ela introduz um novo sentido à história, alterando o vetor dinâmico do tempo que revela sua índole não a partir de algum ponto remoto no passado, mas de algum lugar no futuro. (SEVCENKO, 1992, p. 228, grifo nosso)

Mesmo as menores transformações eram muito celebradas pelos colunistas. Eis uma sequência, em ordem cronológica, de tais fatos:

[... a Prefeitura está estudando o meio mais prático para a numeração dos prédios do perímetro urbano. Consta-nos que será ainda esse mez, que se iniciará o cadastramento para esse devido fim. Tomara que não gore esse grande melhoramento a população, pois que se facilitará extraordinariamente a distribuição de correspondências, reclames comerciais, e tudo enfim que se trata de adiantamento. (NUMERAÇÃO das casas..., 1931, p. 3)

[...] soubemos que o atual prefeito, Snr. Dr. Theodureto F. Gomes, ordenara que se collocasse por definitivo um cadeado no portão do cemitério velho, não consentindo que nessa necrópole seja sepultado nenhum cadáver. Apoiamos esse gesto do Snr. Prefeito, que já há muito deveria ter sido resolvido. Pois desde 1920 que os sepultamentos eram feitos acotoveladamente ou sobrepostos, em virtude da pequena área existente. Pelo que soubemos, S. S. só permitirá os sepultamentos, d'ora avante, no cemitério novo. (ATÉ QUE EMFIM..., 1931, p. 3)

[...] voltou ao corrente a dynamica do anno de 1930, ampliar e dilatar o nosso municipio. Apesar da crise que abala tantos os municipios limitrophes, Ourinhos se enriquece e se immortaliza com o erguimento de soberbos predios. Em todas as ruas da cidade, a febre constructora transpira os seus effeitos. Aparte a construcção dos predios da rua Paraná, São Paulo e Avenida da Saudade, vemos a Praça João Pessoa variar de aspecto com os imponentes predios já construidos e outros em planos de construção. (FEBRE constructora..., 1932, p. 1) 
É digno de registro os abnegados esforços do nosso prefeito, o Sr. Theoduretto F. Gomes no sentido de embellezar a nossa cidade. Assim é que vemos surgir diariamente novas e modernas construcções que vem emprestar mais um cunho de grandeza a este pedaço de São Paulo. Estão completamente reformadas e abauladas as estradas que ligam esta cidade a de Salto Grande, Chavantes e ao porto Mello Peixoto. As nossas ruas estão sendo conservadas, limpas e reformadas. Brevemente pretende ainda o nosso Prefeito iniciar a construcção da Ponte Mello Peixoto. (MELHORAMENTOS..., 1932, p. 1)

Optima, é a impressão que, á primeira vista, apresentam as ruas da cidade ultimamente tratadas com os trabalhos de sargeteamento que a actual administração mandou executar. Evidente, é a vontade de acertar do nosso governador municipal que, diga-se em homenagem a verdade, tem procurado cumprir o seu dever. (SARGETEAMENTO..., 1934, p. 1)

Apesar das condições precárias que se verificavam na cidade de Ourinhos, o imaginário de alguns de seus habitantes estava norteado pelos devaneios oníricos de progresso, riqueza e desenvolvimento ${ }^{6}$. Falas sentimentais eram vistas n'A Voz do Povo e enalteciam o caráter dos habitantes:

[...] segue com afinco as últimas providencias para ser levado a effeito o Espectaculo Patriotico em beneficio do resgate da Dívida Nacional. Pretendem os promotores desse festival ainda esse mez, realizarem os seus desejos para Ourinhos mais que depressa entrar no ról das cidades que occupa logar de destaque em nosso Estado. (ESPECTACULO patriotico..., 1930, p. 2)

Ourinhos, o centro de maior expansão commercial desta rica zona, cidade fadada e ser muito breve a capital do sertão, está se desenvolvendo de maneira estupenda e rapida. Esta cidade está fazendo a sua "toillete". Os velhos casarões de taboas estão sendo demolidos para darem lugar aos grandes e modernos armazens, aos bonitos bangalows e residências chics. O espírito do povo ourinhense é o mesmo do super-homem bandeirante, orgulho de São Paulo, realizador por excellencia, acostumado aos emprehendimentos de vulto; em summa, é o homem do dynamismo cyclopico, que não se afasta até mesmo deante do impossivel. Assim é que, attendendo à ordem emanada da Delegacia regional de Saude de Avaré, diversos commerciantes desta praça estão

6 "O nosso futuro - o futuro desta cidade - é innegavelmente invejavel” (O NOSSO..., 1927, p. 1). reconstruindo seus predios, obedecendo aos requisitos de hygiene. (A HYGIENE em Ourinhos..., 1931, p. 1)

Alguns números possuíam artigos com elogios apaixonados à cidade e tentavam atrair novos moradores para ela ${ }^{7}$, através de descrições de seus bons atributos. Uma fantasia de "terra prometida" era assim construída por meio do discurso do jornal e propagada em seus locais de alcance:

[...] embora novato nesta promissora Ourinhos, onde aportei depois de muito errar por esse mundo de meu Deus, pareceme que já posso gozar do direito e orgulho de fallar sobre sua vida e suas cousas, pois ella, cidade cosmopolita, de costumes francos e camaradagem facilima, é minha segunda Patria. [...] Amigo do progresso, procuro amparar sempre, nos limites de minhas possibilidades, todas as realizações cujas finalidades são quase que sempre exclusivamente de interesse collectivo, não obstante grande parte dellas nascer do genio realizador do elemento extrangeiro, que, irmanado com os que lhe emprestam hospitalidade, nos auxiliam a desbravar os sertões ferocissimos, desvendando mysterios que nem as vistas de lynce do saudoso Euclydes da Cunha conseguiram divisar e só as bandeiras de Antonio Raposo seriam capazes de transpor. (NA SENDA do progresso..., 1934, p. 1)

A praça de Ourinhos vende para quasi todo o norte do Paraná: tecidos, ferragens, materiaes para construcção, bebidas, artigos manufacturados, doces, macarrão, drogas, etc. [...] Ademais, com 3 estradas de ferro, ligando-a directamente a todo o paiz, só póde progredir. [...] Ourinhos tem: Correio, telegrapho, bancos, grupo escolar, um gymnasio particular, drogaria, jardim, musica, cinema, futebol, typographia jornal, optimos hoteis, photographos, fabricas de sabão, macarrão e bebidas, 4 usinas de algodão, egrejas, uma casa de saúde, collectorias estadoal e federal, serrarias,

$7 \quad$ No quinquênio compreendido entre 1932 e 1937, percebeuse a multiplicação de anúncios de vendas e aluguéis de terrenos e casas em Ourinhos, além de constantes propostas de permuta de imóveis. Inclusive, um conflito pelo alto preço dos terrenos foi iniciado em algumas edições, que denunciavam a falta de moradia. "A picareta do progresso, traz, sem duvida, problemas de difficil solução. Um delles, o mais importante é, não ha negar, o da habitação. Ourinhos atravessa, a olhos vistos, uma phase de franco desenvolvimento. Ha falta, rigorosa falta, de casas. [...] Mas, pergunta-se: si não houver uma grande quantidade de predios novos, para onde irão os que aqui vem a procura de casa?... O remedio é a gente não mudar. A menos que a casa cáia” (UM CASO..., 1936, p. 2). 
medicos, dentistas, advogados, cadeia, engenheiros, grandes casas commerciaes e animadissimo commercio varejista. A cidade vae ser calçada e terá rede de êxgotto, em breve. Já tem água potavel. Ourinhos é uma cidade nova e barata. Ha fartura de generos alimenticios. O clima é saudavel. Não ha crise de trabalho. O povo é bom, educado, ordeiro, attencioso e acolhedor. Deixe que seus filhos cresçam nessa cidade que está crescendo. Principie vida nova em uma cidade nova. Aqui ha logar para você e sua familia. Venha conhecer Ourinhos. E fique aqui, que será feliz. (VOCÊ sabia?..., 1937, p. 5)

Na altura de 1937, Ourinhos seria a "cidade movimentada, com seis trens diarios, ponto obrigatorio de passagem diaria de centenas de pessoas" (POLICIAMENTO..., 1937, p. 1), "dezesseis (16) hoteis e pensões e, parece-nos, dez (10) chalets de loteria" (IMPOSTOS..., 1937, p. 2), conforme podemos observar na imagem 2, "Mapa de Ourinhos na década de 1930".

\section{Cidade de Ourinhos: um retrato do pitoresco}

Durante o período de 1927 a 1937, percebemos uma contradição entre a almejada terra dos sonhos, marcada pelo ideal do progresso, e a cidade que de fato existia. A despeito do discurso, o que podemos verificar, tanto nos relatos dos jornais quanto em relatos da população que ali habitava, são as precariedades e dificuldades que marcavam o cotidiano (ROMERO; MORAES, 2004; SILVA, 2009).

No período, as ruas de Ourinhos eram de terra. Possuidora de um fértil solo vermelho, o chamado latossolo, a cidade se tornava um atoleiro em períodos de chuva. Segundo contam Romero e Moraes (2004), caminhões, carros, carroças e pessoas atolavam na lama, chegando a cair de barriga no chão. Além disso, a conservação das ruas era precária, causando várias reclamações entre os colabores do jornal $A$ Voz do Povo:

[...] algumas ruas desta cidade estão num estado tal de conservação que fazem os chauffeurs ter dor de barriga quando transitam por ellas. Essas ruas rivalisam perffeitamente com a sahida da Rua Paraná, onde, dias atraz, o transito era difficillimo, devido os buracos causados pelas ultimas chuvas. É necessário que a Camara conserve nossas ruas, pois é uma vergonha que Ourinhos apresente ruas tão mal conservadas. E as estradas? Só quando ELLE mandar consertar. (REBUSCANDO..., 1927, p. 2)

Tal condição persistiu durante os anos seguintes, como podemos observar em outras passagens:
[...] quem passar por essa via publica, verá o quanto está desleixado o tratamento daquellas sargetas, offerecendo serios perigos aos moradores daquella zona. A referida sargeta é o despejo de águas servidas, lavagens de toda a espécie e assim não poderá continuar por mais tempo. (NA RUA Alagoas..., 1930, p. 3)

Em 1935, o então prefeito Benedicto Martins Camargo receberia uma representação dos munícipes, com 74 assinaturas, com queixas sobre a infraestrutura. O prefeito resolve, então:

[... a) que a poeira suffocante das ruas desta cidade prejudicam em demasia a hygiene e o conforto de seus habitantes [...]; b) que o calçamento imediato das ruas é obra impraticável pela ausencia de recursos financeiros e pela necessidade de antes disso cuidar-se da rêde de exgottos [...]. [Abre então] um credito especial [...] destinado á compra de um caminhão com um tanque e apparelhamento para irrigação. (PREFEITURA Municipal..., 1935, p. 1)

A mesma edição, ao final, elogia o novo prefeito, porém com tom hostil: "[...] Ourinhos em breve terá suas ruas com outro aspecto, pois a julgar pelas reparações que a municipalidade está fazendo na rua Paraná e outras, e de se prever que não mais tenhamos o dissabor de fazer lembrar ao snr. Prefeito o que carecemos" (MELHORAMENTOS locaes..., 1935, p. 7). Dois anos depois, o jornal listaria as ruas que necessitavam de reparo, onde também havia "agua suja e fetida" (BURAQUEIRA..., 1937, p. 5), e ridicularizaria os habitantes mais humildes:

[...] ha individuos refractarios ao progresso. Vivem subjugados pela idéa fixa do passado. Não se enquadram na hora que passa. Vivem fóra de seu tempo. Aqui temos 'algumas reliquias' dessas. São exemplares historicos de uma fauna que, dia mais, dia menos, desaparecerão. Ora, a cidade de Ourinhos, graças ao zelo da administração publica e o arrojo da iniciativa particular, atravessa uma phase de total remodelação. É preciso, pois, que a Camara Municipal, composta na sua unanimidade por uma pleiade de homens praticos, honestos e progressistas, vote uma lei, com rigorosa urgencia, obrigando os proprietarios de tapéras no centro da cidade a demolil-as, ou construirem predios decentes. Não póde, de fórma alguma continuar esse vergonhoso estado de coisas: casarões de taboa, sujos, em ruinas, enfeiando as praças e ruas centraes. Picareta nelles! Casa velha, deshabitada, não dá renda: quem não quer edificar, venda o 'trambolho', 
disponha da 'arapuca'. Quem não tem competencia não se estabelece, diz o dictado. Quem não quer ir para a frente, sáia do caminho. Deixe livre o becco. (XISTO, 1937, p. 5)

Em 1937, a prefeitura mandaria aterrar as ruas centrais e a medida seria comemorada pelo jornal (CONCERTOS..., 1937, p. 2) ${ }^{8}$. Contudo, a situação precária não se restringia apenas às ruas da recém-inaugurada cidade, nem aos primeiros anos de Ourinhos:

A já celebre escada do pateo da Estação Sorocabana desta cidade, esta se candidatando á este titulo. Feita de cimento liso, quasi perpendicular, quem precizar descel-a, nos dias chuvosos, terá de fazer verdadeiros prodigios de acrobacia, se não quizer partir as costellas ou enterrar-se no lamaçal que forma no supra-citado pateo. Já têm despencado do alto daquelle "monumento" diversas pessoas, uma das quaes foi tão infeliz que fracturou o braço. Se o Snr. Director da Sorocabana não sabia disso, fazemol-o sciente para que tome providencia nesse sentido. (ESCADA..., 1934, p. 6)

Aquelle boeiro que está na esquina da Casa Nortista (aquella casa que vende mesmo barato, onde tem aquelle moço alto, elegante, moreno, sympathico), ha muito está requerendo uma desinfecção! O fedor que aquelle infecto boeiro exhala, de nauseabundo, constitue uma ameaça permanente á saúde da população. Sejamos precavidos. Ahi fica o lembrete e... a quem de direitos. (A QUEM..., 1934, p. 6)

O sargeteamento local, de que nos occupamos já em 1934, não tem sido cuidado pelo actual prefeito como esperavamos, pois si alguma cousa nesse sentido fosse iniciada, teve sua paralisação logo após as primeiras labaredas. Não tinhamos pretensão de guerrear, ou melhor, de criticar a actuação do nosso administrador municipal, mas, já que S. S. nos tem feito pouco caso, e ás nossas poucas queixas e reparos absoluto descaso, convém que sahiamos novamente á rua para gritar com a sua incuria a lidar com os negocios municipaes, o que quer dizer, com o nosso negocio [...]. (PROBLEMAS..., 1935, p. 2)

O tema continuaria figurando no jornal nos anos seguintes e, em 1936, um artigo questionou: "Valerá a pena 'gritar' contra a sujeira das ruas? Na Av. Jacintho

8 Seis meses depois, relata-se que a rua que "principia no matadouro e segue rumo á praça fronteira ao campo do Ourinhense, está pedindo a visita do tractor e da plaina do "Sereno"” (RUAS..., 1937, p. 1).
Sá há pontos em que a 'cascaria' tomou conta da sargeta. Como é isto, Sr. Fiscal da Limpeza Publica?" (QUE SUJEIRA..., 1936b, p. 1). O problema seria resolvido apenas entre as gestões dos prefeitos Cândido Barbosa Filho (1948-1951) e Domingos Carmelingo Caló (19521955), quando paralelepípedos, asfalto e rede de esgoto foram instalados.

A água, ainda segundo Romero e Moraes (2004), não era encanada nem limpa, de modo que a população tinha de comprá-la aos garrafões e carroças aguadeiras. Foram os prefeitos Hermelino de Leão (1941-1945) e Antonio Luiz Ferreira (1960-1963) que encanaram a água, vinda do rio Turvo e da Água da Veada, e a trataram, respectivamente. O lixo, segundo denúncias d'A Voz do Povo, era mal recolhido e causava um fétido cheiro pela cidade.

A hygiene collectiva desta cidade, tem preoccupado a attenção do Governo Civil. Para este fim, foi nomeado o novo fiscal o Snr. Nicolau Cardoso, o qual por ordem do distincto Governador deu solução immediata ao nosso pedido do número passado fazendo desaparecer do centro urbano o chiqueiro de porcos situado na Rua Minas Geraes, perto da S. Paulo-Paraná. (JUNTA..., 1930, p. 3)

Nos têm chegado ao conhecimento o descaso com que o encarregado da limpeza publica faz o seu serviço em determinadas pontos da cidade, ás vezes justamente em pontos centraes, onde, segundo nos consta, o lixo encontrado é tirado á prestações, de modos a, quando resolvida a sua total remoção, nem o próprio encarregado da limpesa lhes supporta o cheiro desagradavel e mesmo se repugna ante a massa formidavel de miasmas que delle se apega. (LIXO..., 1935, p. 6)

Approxima-se a época em que a nossa população é presa de molestias mais ou menos epidemicas. [...] Em nosso ultimo numero pedimos a desinfecção de um boeiro que exhala um fetido pestilento. Que nos conste, até hoje, esse coletor continua a ameaçar a integridade sanitaria da população e as autoridades a quem compete o assumpto permanecem inativas. Hoje queremos chamar a attenção da Prefeitura para a imundicie que se verifica na maioria dos açougues da cidade. Tivemos a occasião de VER, num tendal da Rua São Paulo, dezenas e dezenas de ratos de todos os tamanhos, comendo e lambendo peças de carne, que no dia immediato foram vendidas aos freguezes. Todos sabemos que o rato é vehiculo da peste bubonica. Outro facto que depõe contra o zelo administrativo, de quem deve olhar pelo cumprimento das disposições do Codigo de Posturas Municipaes, é o facto 
da carne ser transportada, para os açougues, em carroças comuns, sem o mais leve panno que a separe do assoalho da viatura e sem absoluctamente nada que a proteja da poeira e dos mosquitos. E não foi só por uma vez que sofremos uma repugnancia de ver o conductor da carroça com os pés apoiados sobre a carne destinada ao consumo. Energicas providencias, é o que se espera! (A CARNE..., 1934, p. 6)

A população parecia também não colaborar muito com a limpeza da cidade, deixando tudo a cargo da prefeitura. "As ruas (principalmente as sargetas) estão porquissimas: é lixo, casca de fructas, etc. Por onde andará a Limpeza Publica? Ou terá sido cortada, no orçamento, a verbazinha para esse serviço?” (A CIDADE..., 1936, p. 8) $)^{9}$. A reclamação precisou ser repetida com mais veemência no número seguinte (QUE SUJEIRA!..., 1936a, p. 1$)^{10}$, afinal, o que diriam os diversos visitantes que a cidade recebia sobre os mosquitos e as doenças?

As queixas com relação à iluminação seriam também uma constante n'A Voz do Povo. Em maio de 1931, um artigo de capa denunciava a péssima qualidade e as altas tarifas cobradas pelo serviço de eletricidade, e acusava a Companhia Santa Cruz de irregularidades e quebras contratuais "de facil comprovação" (PAES, 1931a, p. 1), apontando os prejuízos econômicos causados aos produtores de café, que precisavam fazer o beneficiamento dos produtos sem um adequado fornecimento de energia. Nas três edições seguintes (PAES, 1931b, 1931c, 1931d), houve continuação da denúncia, inclusive com provas das acusações, com base nos artigos do contrato descumpridos pela supracitada empresa - "contracto é farrapo de papel?" (PAES, 1931a)-, e enérgicos pedidos de ação por parte da prefeitura.

Na segunda edição, após o retorno, em 1933, o jornal comemoraria as "novas installações que a abalisada Cia. está levantando nos terrenos por ella adquiridos, á Rua Piahuy" (CIA. FORÇA..., 1933, p. 6). "Já não tem conta as vezes que temos clamado por Luz e energia electricas dessa empreza que tem por 'Kahal' esta vastíssima e rica região [...]" (FORÇA..., 1936, p. 6). Os moradores também procurariam o jornal para reclamar que uma das mais importantes e mais movimentadas ruas da cidade

9 Uma nota, um ano depois, apelava para que a população das ruas centrais apenas depositasse o lixo durante a manhã (LIXO..., 1937, p. 5).

10 Em 1937, uma notinha reclamava de um "exgotto visível" à rua Antonio Prado (AGUA suja!..., 1937, p. 5). "não tem illuminação efficiente. Á noite, a rua é iluminada quase pelas... lampadas das casas..." (LUZ!..., 1936b, p. 7$)^{11}$. No ano seguinte, a iluminação ainda seria alvo de reclamações (ESGURIDÃO..., 1937, p. 2; A LUZ..., 1937, p. 5; A LUZ ELECTRICA..., 1937, p. 1).

Aproveitando-se das eleições de 1936, integralistas elencaram uma lista de 12 itens em que figuravam:

[...] $1^{\circ}$ - Rêde de Exgottos e calçamento; $2^{\circ}$ - Revisão do contracto de fornecimento de luz e força; $3^{\circ}$ - Completa remodelação dos serviços de abastecimento de agua; [...]. $7^{\circ}$ - Perfeito serviço de conservação de estradas de rodagem e estudo e construcção de novas rodovias, afim de desenvolver a vida do município e da cidade; $8^{\circ}$ - Matadouro Municipal; $9^{\circ}$ - Jardim Publico. (SEGÇÃO..., 1936, p. 10)

Quase um mês depois, a questão da luz seria considerada "quasi um mal chronico. Não é de hoje que o povo roga, pede, supplica á digna concessionaria um pouquinho de bôa vontade para esse verdadeiro tormento" (O CASO ..., 1936, p. 3). Dois meses depois, seria hora de, utilizando mais ironia, reclamar novamente: "a luz de Ourinhos anda soffrendo dos 'nervos' e dos 'olhos' é só no 'pisca-pisca', no 'apaga-apaga' ... Um trovão, um relampago, um ventinho mais forte e é aquella agua..." (LUZ!..., 1936, p. 1) $)^{12}$.

No ano seguinte, o jornal classificou a luz de Ourinhos como "a peior luz da Sorocabana", lamentou que "uma cidade, que cresce dia para dia, esteja tão mal illuminada" e desafiou o presidente da companhia de luz a "lêr um jornal debaixo de uma lampada de 100 velas!" (ILLUMINAÇÃO..., 1937, p. 1) 13.

A descrença no poder público era tamanha que na edição 296 o periódico apelava para que os próprios comerciantes colocassem iluminação "na frente

11 Quase um ano depois, as queixas seriam que "a luz electrica continúa muito fraquinha e, tambem, muito inconstante" (A LUZ..., 1937b, p. 5). A edição n 287 comemorava a inauguração de luz elétrica no bairro do matadouro (LUZ!..., 1937, p. 1).

12 A edição n 249 reclamava de "diversas lampadas apagadas [na cidade]" e exigia providências da prefeitura, uma vez que o fornecimento da luz é "cara e ruim" (MAS, QUE..., 1936, p. 8). As próximas edições trariam reclamações também (ILLUMINAÇÃO..., 1936, p. 1; LUZ!..., 1937a).

13 "Quem chega a Ourinhos, á noite, duvida que a cidade tenha illuminação electrica [...] Essa que temos é pouca. Curta. Fraca. Mais luz!” (A LUZ!..., 1937, p. 2). 
do seu negocio, uma ou duas lampadas de 200 velas" (UMA..., 1937, p. 1). No final do período analisado do jornal, as denúncias e reclamações sobre a eletricidade se mantiveram e, segundo os relatos, rendiam muito atrito entre moradores e o poder público. Garantir o uso desse serviço valia o status de desenvolvimento e de civilidade, chancelando aspirações e sonhos de uma cidade que erigia para si mesma os símbolos de progresso.

Outro símbolo de progresso se constituía na praça Mello Peixoto, que foi remodelada diversas vezes. Emblema de orgulho da cidade por ser o único "Largo" ourinhense, ela era alvo constante de reclamação diante do desleixo da prefeitura:

[...] prossegue, a passo de boi velho, a capina da 'invernada' do ex-jardim da Praça Mello Peixoto. [...] 'Progresso'... Espectaculo desolador é o que offerece a Praça [...]. Não fồra o intenso trafego de pedestres e o movimentado 'footing' domingueiro e nos atreveríamos a compara o unico Largo da nossa cidade com um desses pomares abandonados lá para o lado da Central depois da Lei Aurea, tal o modo descuidado por que crescem aquellas infelizes arvores. (CAPINA..., 1936, p. 2)

Quase dois meses depois, o ego ourinhense ainda ressentia a má conservação de sua única praça (OJARDIM..., 1936, p. 5) $)^{14}$ :

nem sabemos si merece o nome de jardim esse grammado da Praça Mello Peixoto. Não tem esthetica nem limpeza. É uma imitação burlesca de jardim. [...] Jardim, no conceito unanime de Simões da Fonseca, Jayme de Seguier, Candido de Figueiredo, Aulette, Moraes e outros mestres, é: 'terreno onde se cultivam flôres, plantas, etc. Cadê as flores de nosso jardim? O gato comeu... (OJARDIM..., 1936, p. 5)

Finalmente, ainda em uma edição de 1936, caberia uma notinha elogiando a "remodelação do jardim [...] vamos ter, em breve, um jardim que será um mimo" (UM BELLO..., 1936, p. 8 $)^{15}$. Mais elogios seriam direcionados à remodelação do jardim e o periódico mal disfarçava

14 A edição de 13 de junho de 1936 dava como certa a reforma para a próxima semana e, na edição seguinte, de $20 \mathrm{de}$ junho de 1936, desafia: "É mais logico, mais razoavel que esses assumptos, de maxima importnacia, sejam resolvidos pela proxima [estavel e constitucional] Camara Municipal de Ourinhos" (ASPECTO..., 1936, p. 3).

15 Dois meses depois, seguiam os elogios (MAS, QUE..., 1937, p. 5). a ansiedade por sua inauguração (OJARDIM..., 1937, p. 1; QUASI..., 1937, p. 2) ${ }^{16}$. O grande dia chegaria em 11 de julho de 1937, quando estariam presentes as "pessôas mais representativas [daquela] sociedade" (AMANHÃ!..., 1937, p. 2) ${ }^{17}$.

Nos anos posteriores, como recorda o professor Norival Vieira da Silva (2009), a praça "sempre foi esquecida por todas as administrações públicas, sem exceção. Inventaram algumas reformas no correr dos anos que só destruíam e nada acrescentavam de belo e significativo" (SILVA, 2009, p. 172). Ele ainda tece muitos elogios ao lugar, dada a sua importância afetiva: "olho você e me lembro: a praça do Jardim, nome que era seu. O jardim, as fontes, seu coreto se foram, mas você ficou" (Ibidem). Contudo, mesmo tocado, não deixaria de lamentar: "sabe, você continua como o centro, o coração, mas não é a mais bonita. Você ficou triste, escura à noite" (SILVA, 2009, p. 173).

\section{Cidade de Ourinhos: a moral e os bons costumes}

Nem só de flagelos estruturais da cidade os ourinhenses viviam. No período analisado por nós, embora não seja uma particularidade desse recorte, é possível perceber um discurso cada vez mais moralista ${ }^{18}$. Esse jornal, que sempre se disse representante do povo ${ }^{19}$, como o próprio nome procura frisar, era, na verdade, a voz da burguesia que se fazia crescente na cidade. Qualquer sinal de pobreza ou atraso necessitava ser rapidamente varrido dos contornos urbanos e dos olhares pudicos da população ${ }^{20}$, já que comprometiam o tão sonhado

16 "O coreto, pintadinho de branco, põe agua na bocca dos 'fans' da bôa musica” (O JARDIM...., 1937, p. 1).

17 Contudo, ainda houve reclamações (BANCOS..., 1937, p. 1).

18 Afirmamos isso com base em outro periódico que circulou num período posterior, com o qual também tivemos a oportunidade de trabalhar. Vide: Cunha et al., 2012.

19 O primeiro número, por exemplo, faz apelos à população de que prestigiem o jornal por ser "a tribuna de onde o povo lançará os seus vehementes brados de protesto, quando menosprezados em seus sacrosantos direitos" (A VOZ..., 1927, p. 1).

20 "O poder público tentava criar uma geografia social definindo os lugares das pessoas" (PEREIRA, 2004, p. 46). "A picareta do progresso [...]" (UM CASO..., 1936, p. 2). 'Aqui, temos 'algumas reliquias' dessas. São exemplares historicos de uma fauna que, dia mais, dia menos, desapparecerão" (AS TAPÉRAS..., 1937, p. 5). 
progresso. Por vezes, é possível notar, na reiteração de um símbolo como um largo ou jardim, que o olhar do jornal e de seus redatores estava voltado apenas para si:

[...] a convivência diária com camelôs, moradores de rua, assaltos, trânsito difícil, poluição, ou seja, com uma longa série de problemas, faz do morador da grande cidade uma presa fácil da violência, das condições de vida degradada. Falar de violência urbana, considerando somente vitimada a parcela formalmente instalada da população, constitui sem dúvidas um ato violento. $\mathrm{O}$ drama urbano tem duas faces, e com certeza a mais bárbara constitui a da negação das contradições humanas mínimas para a população pobre, desempregada e mesmo para parte da formalmente inserida no mercado de trabalho. (BRESCIANNI, 1998, p. 247)

Afirmamos isso com base nas constantes reações de repressão e exageros quando se tratava da parte mais pobre da população ${ }^{21}$ :

[...] a rua Alagoas, todas as noites é theatro das maiores e mais profanas revelias. Ali, é só declinar a tarde e... já os pertubadores da ordem e do socego publico põe em pratica as suas boas qualidades; e a intranquilidade reina até alta madrugada. Não obstante estes, existe nessa rua uma casa de tolerancia, cujas mulheres, não medindo a gravidade de suas faltas perante o bom senso, bastante inescrupulosas promovem a mais estupida e vergonhosa imoralidade com palavrões, obcenidades e tregeitos que seria capaz de fazer corar até as proprias pedras. [...] Quando, á tardinha, algumas familias que habitam esta cidade de ha longos annos, e portanto de tradições louvaveis, transitavam por aquella via publica, eis que duas mulheres de vida facil, das mais indecentes que a ideia humana e de bom senso possa conceber, se atracam em plena rua provocando os maiores e mais nojentos escândalos. (COISAS..., 1931, p. 4, grifo nosso)

Era interessante para o periódico explicitar pares de opostos bem delineados: a família de tradições louváveis e os perturbadores da ordem e do sossego. A perseguição às "mulheres de vida fácil" pode ser vista, com certa frequência, estampada nas páginas do jornal:

21 "Parece-nos que a camada popular estava incluída somente no que se refere à moralização de seus atos, ao controle de suas práticas e costumes, e à desapropriação de suas moradas" (PEREIRA, 2004, p. 38).
[...] esteve em nossa redacção, dando-nos o prazer de sua amavel visita $[\ldots]$ mui correcto Delegado de Policia local. S. S., com a lhaneza de trato que o caracterisa, communicou-nos que como medida preventiva e acauteladora do socego publico, havia tomado a resolução de fazer habitar os recantos afastados da cidade; as meretrizes que até ha pouco viviam por ahi, entremeadas com familias. É esta uma medida á qual prestamos nosso inteiro apoio e que muito concorrerá para que Ourinhos, lá fóra, eleve ainda mais o bom conceito em que é tida. (CAMPANHA..., 1934, p. 2)

O relato procura, além de mostrar o desprezo às meretrizes $^{22}$, posicionar o "mui correto delegado de polícia" ao lado do jornal e da população ourinhense (de bem). Oculta-se, nessa passagem, os clientes das tais "mulheres de boas qualidades". Trata-se de um recurso muito conhecido do período, a dupla moral ${ }^{23}$, que:

[... ficava expressa na forma como o poder público e científico preocupou-se em tomar providências quanto à vigilância das prostitutas, mas quanto aos homens que as procuravam, bem como àqueles que apresentavam sinais da doença [sífilis], pouco fizeram. O máximo que esses poderes faziam com relação a esses homens era recomendar repouso e afastamento temporário do trabalho, a fim de eles se curarem da moléstia. (PEREIRA, 2004, p. 87)

Nas páginas d'A Voz do Povo, havia uma excessiva campanha em prol da sexualidade com uma coluna médica, presente em quase todas as edições. O ensino da sexualidade era responsabilidade dos médicos, mas também da família: ela deveria ser tratada como ciência, como um ramo da biologia ${ }^{24}$. Porém, os assuntos eram tratados de forma muito superficial e remédios para diversas doenças, inclusive para a sífilis, apareciam sempre no jornal ${ }^{25}$.

22 "As prostitutas impediam que a população alcançasse o nível de civilização desejado” (PEREIRA, 2004, p. 26).

23 É o caso dessa edição, segundo a qual as "casas de tavolagem $[\ldots]$ contribue para a corrupção de menores que para ellas se dirigem havidos por uma distracção qualquer e dahi o se desviarem" (CASAS..., 1935, p. 1).

24 O assunto foi alvo de uma coluna fixa por dez semanas consecutivas, intitulada "Eduquemos nossa mocidade", que durou de 2 de maio de 1936 a 11 julho de 1936. Esses são apenas outros exemplos: Albuquerque (1934a, 1934b, 1935a, 1935b).

25 Um exemplo é o "Elixir de Nogueira". Há na edição de número 66 a referência à visita de um médico, o dr. Mario 
Os contundentes termos utilizados para categorizar a pobreza, transformando-a quase num sinônimo de criminalidade ${ }^{26}$, lembra-nos as "classes perigosas": "isto significa dizer que o fato de ser pobre torna o indivíduo automaticamente perigoso à sociedade. Os pobres apresentam maior tendência à ociosidade, são cheios de vícios, menos moralizados e podem facilmente 'rolar até o abismo do crime"' (CHALHOUB, 2012, p. 76). Nesse sentido, a polícia era constantemente chamada a cumprir seu dever quando se tratava de batedores de carteira e assaltantes ${ }^{27}$, menores problemáticos ${ }^{28}$, gatunos ${ }^{29}$, perturbadores da or-

R. Pimentel, autor de uma dissertação sobre a sífilis (VISITA..., 1931, p. 1).

26 "Ideologicamente quase se equivalem os conceitos de pobreza, ociosidade e criminalidade" (CHALHOUB, 2012, p. 80).

27 "A policia está no dever de tomar severa attitude no combate aos batedores de carteira. Á hora de chegada dos trens quando é intenso o movimento de passageiros, os 'punguistas' agem audaciosamente [...]" (BATEDORES, 1936, p. 8.; BATEDORES..., 1937a, p. 1.; BATEDORES, 1937b, p. 1.; ASSALTO..., 1933, p. 6.; FOI assalto!..., 1937, p. 6).

28 "É dever do Poder Publico fiscalizar, severamente, a conducta das creanças que vivem perambulando pelas ruas. Temos em Ourinhos, um caso serissimo para ser resolvido pela Polícia, ou pela Prefeitura: os pequenos engraxates que, inconscientemente, expostos ao sol e a poeira, sujeitos a corrupção moral, infestam as ruas. [...] Si tem paes validos, a estes cabe trabalhar para sustentar e educar seus filhos" (COM A POLICIA..., 1936, p. 1). "Não podemos comprehender a indifferença de nossos dirigentes, em face das creanças pobres que, em Ourinhos, enchem as ruas, promovendo algazarra, aprendendo vicios e penetrando, inconscientemente, no campo nefasto da malandragem" (OS ENGRAXATES..., 1936, p. 1). "Esses gurys, conhecidissimos pelas suas atitudes duvidosas, vivem ao Deus dará, prejudicando o socego publico" (MENORES..., 1937a, p. 6). "Esse gurys, na sua maioria, não sabem o Padre Nosso, nem conhecem o A-B-C, mas imitam direitinho TOM MIX, BUCK JONES e torcem pela 'mocinha' e pelo 'bandidão"' (MENORES...,1937b, p. 5; MENORES ..., 1937c, p. 1; MOLEQUES..., 1937, p. 5; TOM MIX...., 1937, p. 1).

29 "Infelismente temos a registrar, que nesta cidade deve haver por força uma 'trempe' de gatunos tão escovados, que chegam ao ponto de roubar com tanta pericia desafiando a nossa ordeira policia [...]. Aqui já estamos em eminencia de descobrir os meliantes, visto um dos taes ja estar engaiolado e entregue a justiça para pagar caro o tributo do pouco amor ao trabalho e tão sagazmente cometer, delictos dos mais antepathicos que se possa narrar" (OS LADRÕES..., 1936, p. 1; ROUBOS..., 1931, p. 1). dem pública $^{30}$ e forasteiros ${ }^{31}$. Os jovens pobres, ao menos no Natal, quando era feita uma campanha de arrecadação de donativos, poderiam ter "a illusão, embora ephemera, de que a humanidade não esqueceu o 'amar a Deus sobre todas as coisas e ao proximo como a nós mesmos" (NATAL..., 1937, p. 5).

Polícia ${ }^{32}$ e médicos seriam as duas figuras constantemente destacadas no jornal: a primeira para reprimir os discordantes do modelo de progresso e a segunda para justificar os preceitos de uma educação higiênica que abrangia a saúde do trabalhador, da casa e da cidade, contudo, "mascarados pelos seus propósitos declaradamente científicos, reforçavam formas de dominação e de manutenção e de reprodução da ordem social burguesa" (CHALHOUB, 2012, p. 77).

Era necessário produzir um discurso que ignorasse as contradições na produção de uma cidade do progresso que pertencia a poucos, jogando o ônus do sistema capitalista para o indivíduo, num discurso meritocrático. Por isso, o trabalhador era outro alvo constante da moralidade: seu local de moradia e sua responsabilidade com os compromissos econômicos eram ridiculariza$\operatorname{dos}^{33}$, de modo que deveria saber seu lugar, respeitar

30 "Moços mal educados e sem qualquer noção das bôas normas de conducta, por ocasião dos footings em volta do jardim, $[\ldots]$ instigam a molecada á pratica de actos condemnaveis, [...]. Seria de bom alvitre pois, que a policia tomasse uma providencia para o caso, enlaçando essa molecada no cinturão" (A POLICIA..., 1935, p. 1).

31 "Ponto de convergencia de gente de todo o kilate, [...] gente de todas as nacionalidades e que, as vezes, á cata de ocupação, se infiltram por entre todas as camadas, constituindo grande perigo aos cidadãos pacatos. Andar armado é prohibido. [...] basta que o patrulhamento seja feito com rigor para que os forasteiros desocupados que por ahi perambulam procurem um meio ou de procurar trabalho ou darem o fóra” (OS FORASTEIROS..., 1935, p. 2).

32 "A imposição do assalariamento ao trabalhador é corroborada pela vigilância constante do aparato policial, que rotula de 'vadios' - e arremessa eventualmente ao xilindró - todos aqueles indivíduos que se encontram em botequins e nas ruas e que não conseguem provar sua condição de trabalhadores isto é, de indivíduos submetidos ou adaptados ao projeto de vida feito para eles" (CHALHOUB, 2012, p. 255).

33 "Ha grande falta de casas de aluguel na cidade, principalmente casas para operarios, e quando ha, custa quase que mensalmente o ordenado do pobre trabalhador. Porque os Lazards Brothers da cidade não empregam o seu capital na construção de residencias para o proletariado? Será que têm medo do calote?" (O PROBLEMA..., 1935, p. 2). 
seus patrões, cumprir suas obrigações e ficar afastado do comunismo (INFILTRAÇÕES..., 1935, p. 2 e p. 6), do alcoolismo ${ }^{34}$ e dos bares, pois:

[...] a ociosidade deve ser combatida não só porque negando-se ao trabalho o indivíduo deixa de pagar sua dívida para com a sociedade, mas também porque o ocioso é um pervertido, um viciado que representa uma ameaça à moral $\mathrm{e}$ aos bons costumes. Um indivíduo ocioso é um indivíduo sem educação moral, pois não tem noção de responsabilidade, não tem interesse em produzir o bem comum nem possui respeito pela propriedade. (CHALHOUB, 2012, p. 74)

\section{CONSIDERAÇÕES FINAIS}

Embora a memória de Ourinhos tenha sido sedimentada pelos memorialistas como o "útero do progresso", é notável, através d'A Voz do Povo, que havia percalços e obstáculos a esse sonho.

De um lado, os colaboradores do jornal se utilizavam de ironias e do poder do jornal para chamar a atenção para suas demandas e, com isso, aproximarem a si e a cidade, cada dia mais, do tão almejado progresso. Contudo, de outro lado, havia a precária infraestrutura, moradores mais humildes, as mulheres que fugiam às regras sociais e os casebres e "taperas" que se configuravam em duro obstáculo para a realização do desejo da minoria burguesa.

O resultado de tal embate foi o silenciamento da classe mais baixa, que teve não só suas moradias, mas também seus valores e costumes varridos para as periferias da cidade, sem fazer parte da sonhada "urbe" de poucos.

\section{REFERÊNCIAS}

A CIDADE... A Voz do Povo, Ourinhos, p. 8, 6 jun. 1936.

A CARNE e os açougues.... A Voz do Povo, Ourinhos, p. 6, 28 out. 1934 .

34 "O combate ao alcoolismo esteve presente nas diferentes cidades da sociedade ocidental cristã, com o objetivo de disciplinar os trabalhadores. Os industriais foram os principais interessados em divulgar medidas contra o alcoolismo que causava tantas faltas ao trabalho" (PEREIRA, 2004, p. 83).
A HYGIENE em Ourinhos.... A Voz do Povo, Ourinhos, p. 1, 6 dez. 1931.

A LUZ electrica.... A Voz do Povo, Ourinhos, p. 1, 3 jul. 1937a.

A LUZ tremeu!... A Voz do Povo, Ourinhos, p. 5, 23 jan. 1937b.

A LUZ!.... A Voz do Povo, Ourinhos, p. 2, 10 jul. 1937.

A LUZ.... A Voz do Povo, Ourinhos, p. 5, 26 jun. 1937.

A POLICIA precisa ver isso.... A Voz do Povo, Ourinhos, p. 1, 15 jun. 1935.

A QUEM de direitos... A Voz do Povo, Ourinhos, p. 6, 21 out. 1934.

AGUA suja!.... A Voz do Povo, Ourinhos, p. 5, 13 fev. 1937.

AGUIAR, L. M. B. O ensino de ciências nos atlas escolares: entre temas, professores e pesquisas. Cadernos Cedes, Campinas, v. 23, n. 60, p. 198209, ago. 2003. Disponível em: https://bit.ly/3iUkAjH. Acesso em: 7 set. 2018.

ALBUQUERQUE, J. A educação sexual na puberdade. A Voz do Povo, Ourinhos, p. 4, 16 set. 1934a.

ALBUQUERQUE, J. Controversias sexologicas. A Voz do Povo, Ourinhos, p. 2, 11 nov. 1934b.

ALBUQUERQUE, J. A educação sexual pela imagem. A Voz do Povo, Ourinhos, p. 1, 1 jun. 1935a.

ALBUQUERQUE, J. Educação sexual e libidinagem. A Voz do Povo, Ourinhos, p. 1, 8 jun. 1935b.

AMANHÃ!..... A Voz do Povo, Ourinhos, p. 2, 10 jul. 1937.

ARAUJO, J. L. B. A cidade de Ourinhos e suas memórias e representações histórico-cartográficas: os Kaingangs (século XIX); a Ferrovia (a partir de 1908) e a malha urbana (entre as décadas de 1930 a 1940). 2021. 152 p. Dissertação (Mestrado em Geografia) Instituto de Geociências e Ciências Exatas, Universidade Estadual Paulista, Rio Claro, 2021. 
ARAUJO, J. L. B.; CUNHA, F. L. Cotidiano e moral ourinhense: análise do jornal $A$ voz do Povo entre 1927 e 1932. Revista Geografia e Pesquisa, Ourinhos, v. 11, n. 1, p. 3239, 2017.

ASPECTO bonito.... A Voz do Povo, Ourinhos, p. 3, 20 jun. 1936.

ASSALTO e roubo.... A Voz do Povo, Ourinhos, p. 6, 20 ago. 1933.

AS TAPÉRAS.... A Voz do Povo, Ourinhos, p. 5, 23 jan. 1937.

ATÉ QUE EMFIM.... A Voz do Povo, Ourinhos, p. 3, 26 abr. 1931.

A VOZ do povo.... A Voz do Povo, Ourinhos, p. 1, 9 jan. 1927.

BANCOS, cercas \& lampadas.... A Voz do Povo, Ourinhos, p. 1, 17 jul. 1937.

BATEDORES de carteira.... A Voz do Povo, Ourinhos, p. 8, 1 ago. 1936.

BATEDORES de carteira.... A Voz do Povo, Ourinhos, p. 1, 7 ago. 1937a.

BATEDORES de carteira.... A Voz do Povo, Ourinhos, p. 1, 21 ago. 1937b.

BOSCARIOL, R. A. Formação socioespacial e expansão urbana do município de Ourinhos / SP. 2008. 170 p. Trabalho de Conclusão de Curso (Bacharelado em Geografia) - Universidade Estadual Paulista, Campus Experimental de Ourinhos, São Paulo, 2008.

BOSI, E. Memória e sociedade: lembranças de velhos. 12. ed. São Paulo: Companhia das Letras, 1994.

BRESCIANNI, M. S. M. História e historiografia das cidades, um percurso. In: FREITAS, M. C. (org.). Historiografia brasileira em perspectiva. 2. ed. São Paulo: Contexto, 1998. p. 237258.

BURAQUEIRA... A Voz do Povo, Ourinhos, p. 5, 10 jul. 1937.
Campanha ao meretricio.... A Voz do Povo, Ourinhos, p. 2, 4 mar. 1934.

CAPINA.... A Voz do Povo, Ourinhos, p. 2, 15 fev. 1936.

CASAS de tavolagem.... A Voz do Povo, Ourinhos, p. 1, 26 jun. 1935.

CHALHOUB, S. Trabalho, lar e botequim: cotidiano dos trabalhadores do Rio de Janeiro da belle époque. 3. ed. Campinas: Editora da Unicamp, 2012.

CIA. Força e Luz.... A Voz do Povo, Ourinhos, p. 6, 16 jul. 1933.

COISAS vergonhosas.... A Voz do Povo, Ourinhos, p. 4, 1 mar. 1931.

COM A Policia.... A Voz do Povo, Ourinhos, p. 1, 14 nov. 1936.

COncertos de rua.... A Voz do Povo, Ourinhos, p. 2, 31 jan. 1937.

COSTA, A. M.; SCHWARCZ, L. M. 1890-1914: no tempo das certezas. São Paulo: Companhia das Letras, 2000.

CUNHA, F. L; SILVA, G. A.; AZORLI, D; F. R.; FREIRE, R. B. Memórias escolares: uma reconstrução da História da E. E. Horácio Soares em Ourinhos/SP. In: Congresso Internacional sobre a Teoria HistóricoCultural, 1., 2012, Marília.

DEL RIOS, J. Ourinhos: memórias de uma cidade paulista. 2. ed. rev. aum. Cornélio Procópio: UENP, 2015.

DIAS, F. M. F. A gênese de Ourinhos/SP: a cidade "acima da linha" e "abaixo da linha". Geoingá, v. 6, n. 1, p. 4661, 2014.

ESCADA da morte.... A Voz do Povo, Ourinhos, p. 6, 1 jul. 1934.

ESGURIDÃO.... A Voz do Povo, Ourinhos, p. 2, 19 jun. 1937.

espectaculo patriotico.... A Voz do Povo, Ourinhos, p. 2, 7 dez. 1930. 
FEBRE constructora.... A Voz do Povo, Ourinhos, p. 1, 10 jan. 1932 .

FOI ASSALTO.... A Voz do Povo, Ourinhos, p. 6, 9 out. 1937.

FORÇA que não.... A Voz do Povo, Ourinhos, p. 6, 18 jan. 1936.

GIMÉNEZ, G. Materiales para una teoría de las identidades sociales. Frontera Norte, Tijuana, v. 9, n. 18, p. 928, 1997.

HALBWACHS, M. A memória coletiva. 2. ed. Tradução: Beatriz Sidou. São Paulo: Centauro, 2006. 7. reim., 2013.

IlluminaçÃ̃O.... A Voz do Povo, Ourinhos, p. 1, 28 nov. 1936.

ILluminaÇÃ̃ .... A Voz do Povo, Ourinhos, p. 1, 19 jun. 1937.

IMpostos.... A Voz do Povo, Ourinhos, p. 2, 18 set. 37.

INAUGURAÇÃ̃ da nova estação.... A Voz do Povo, Ourinhos, p. 2, 20 mar. 1927.

INFILTRAÇÕES communistas.... A Voz do Povo, Ourinhos, p. 2: p. 6, 21 dez. 1935.

JUNTA revolucionária.... A Voz do Povo, Ourinhos, p. 3, 7 dez. 1930.

LE GOFF, J. História e memória. 5. ed. Campinas: Unicamp, 2003.

LIXO .... A Voz do Povo, Ourinhos, p. 6, 15 jun. 1935.

LIXO.... A Voz do Povo, Ourinhos, p. 5, 17 jul. 1937.

LUZ!.... A Voz do Povo, Ourinhos, p. 7, 29 fev. 1936a.

LUZ!.... A Voz do Povo, Ourinhos, p. 1, 9 maio 1936b.

LUZ! .... A Voz do Povo, Ourinhos, p. 1, 18 maio 1937a.

LUZ!.... A Voz do Povo, Ourinhos, p. 1, 29 maio 1937b.
MAS, QUE belleza!.... A Voz do Povo, Ourinhos, p. 5, 23 jan. 1937.

MAS, QUE relaxamento.... A Voz do Povo, Ourinhos, p. 8, 15 ago. 1936.

Melhoramentos locaes.... A Voz do Povo, Ourinhos, p. 7, 20 jul. 1935.

Melhoramentos.... A Voz do Povo, Ourinhos, p. 1, 1 maio 1932 .

MENORES vadios.... A Voz do Povo, Ourinhos, p. 6, 26 jun. 1937a.

MENORES vadios.... A Voz do Povo, Ourinhos, p. 5, 10 jul. $1937 \mathrm{~b}$.

MENORES vadios.... A Voz do Povo, Ourinhos, p. 1, 06 nov. 1937c.

MOlequeS.... A Voz do Povo, Ourinhos, p. 5, 9 out. 1937.

NA RUA Alagoas.... A Voz do Povo, Ourinhos, p. 3, 7 dez. 1930.

NA SENDA do progresso. A Voz do Povo, Ourinhos, p. 1, 4 mar. 1934.

NATAL dos pobres.... A Voz do Povo, Ourinhos, p. 5, 6 nov. 1937.

NORA, P. Entre memória e história: a problemática dos lugares. Projeto História, São Paulo, n. 10, 1993, p. 728.

NUMERAÇÃ̃ das casas.... A Voz do Povo, Ourinhos, p. 3, 1 mar. 1931 .

O CASO da luz.... A Voz do Povo, Ourinhos, p. 3, 28 mar. 1936.

OJARDIM.... A Voz do Povo, Ourinhos, p. 5, 4 abr. 1936.

O JARDim.... A Voz do Povo, Ourinhos, p. 1, 19 jun. 1937.

O nOsso futuro.... A Voz do Povo, Ourinhos, p. 1, 16 jan. 1927 . 
O PROBlema de habitações.... A Voz do Povo, Ourinhos, p. 2, 8 jun. 1935.

Os engraxates.... A Voz do Povo, Ourinhos, p. 1, 21 nov. 1936.

Os forasteiros.... A Voz do Povo, Ourinhos, p. 2, 22 jun. 1935.

OS LADRÕeS.... A Voz do Povo, Ourinhos, p. 1, 12 set. 1936.

PAES, R. Luz e Força, Pessima e Cara, isso É que Sim! A Voz do Povo, Ourinhos, p. 1, 10 maio 1931a.

PAES, R. Luz e Força, Pessima e Cara, isso É que Sim! A Voz do Povo, Ourinhos, p. 1, 17 maio 1931b.

PAES, R. Luz e Força, Pessima e Cara, isso É que Sim! A Voz do Povo, Ourinhos, p. 1, 31 maio 1931c.

PAES, R. Luz e Força, Pessima e Cara, isso É que Sim! A Voz do Povo, Ourinhos, p. 1, 14 jun. 1931d.

PEREIRA, I. "As decaídas": prostituição em Florianópolis (1900-1940). Florianópolis: UFSC, 2004.

POLICIAMENTO.... A Voz do Povo, Ourinhos, p. 1, 21 ago. 1937.

POLLAK, M. Memória e identidade social. Estudos Históricos, Rio de Janeiro, v. 5, n. 10, p. 200212, 1992.

POULET, G. O espaço proustiano. Rio de Janeiro: Imago, 1992.

PREFEITURA Municipal.... A Voz do Povo, Ourinhos, p. 1, 20 jul. 1935.

PROBLEMAS de summa importancia para Ourinhos, que o snr. prefeito custa a solucionar.... A Voz do Povo, Ourinhos, p. 2, 6 jul. 1935.

QUASI TERMINADO... A Voz do Povo, Ourinhos, p. 2, 10 abr. 1937.

QUE SUJEIRA!.... A Voz do Povo, Ourinhos, p. 1, 13 jun. 1936 a.
QUE SUJEIRA.... A Voz do Povo, Ourinhos, p. 1, 8 ago. 1936b.

RebUSGando.... A Voz do Povo, Ourinhos, p. 2, 30 jan. 1927.

ROMERO, F. S; MORAES, R. R. Um espaço para lembranças de Ourinhos. Ourinhos: Prefeitura Municipal, 2004.

ROUBOS .... A Voz do Povo, Ourinhos, p. 1, 26 abr. 1931.

RUAS.... A Voz do Povo, Ourinhos, p. 1, 24 jul. 1937.

Sargeteamento.... A Voz do Povo, Ourinhos, p. 1,17 jun. 1934.

SECÇÃO livre.... A Voz do Povo, Ourinhos, p. 10, 29 fev. 1936.

SEVCENKO, N. Literatura como missão: tensões sociais e criação cultural na Primeira República. São Paulo: Brasiliense, 1999.

SEVGENKO, N. Orfeu extático na metrópole: São Paulo, sociedade e cultura nos frementes anos 20. São Paulo: Companhia das Letras, 1992.

SILVA, N. V. Ourinhos em crônicas. Ourinhos: Edições Cristãs, 2009.

TOM mix.....A Voz do Povo, Ourinhos, p. 1, 19 jun. 1937.

UMA bôa illuminação.... A Voz do Povo, Ourinhos, p. 1, 10 jul. 1937.

UM BELLO jardim.... A Voz do Povo, Ourinhos, p. 8, 14 nov. 1936.

UM CASO serio!.... A Voz do Povo, Ourinhos, p. 2, 13 jun. 1936.

VISITA... A Voz do Povo, Ourinhos, p. 1, 19 jul. 1931.

VOCÊ sabia?.....A Voz do Povo, Ourinhos, p. 1, 16 out. 1937.

XISTO. As tapéras.... A Voz do Povo, Ourinhos, p. 5, 23 jan. 1937. 